Supporting Information for

\title{
3D Photochemical Printing of Thermally Activated Polymer Foams
}

Soyoung E. Seo, ${ }^{1,2}$ Younghoon Kwon, ${ }^{3}$ Neil D. Dolinski, ${ }^{1,2}$ Caitlin S. Sample, ${ }^{1}$ Jeffrey L. Self, ${ }^{4}$ Christopher M. Bates, ${ }^{1,2,4}$ Megan T. Valentine, ${ }^{*, 2,3}$ Craig J. Hawker ${ }^{*, 1,2,4}$

\footnotetext{
${ }^{1}$ Materials Department, University of California, Santa Barbara, California 93106 ${ }^{2}$ Materials Research Laboratory, University of California, Santa Barbara, California 93106

3Department of Mechanical Engineering, University of California, Santa Barbara, California 93106

${ }^{4}$ Department of Chemistry and Biochemistry, University of California, Santa Barbara, California 93106
}

*Address correspondence to:

hawker@mrl.ucsb.edu and valentine@engineering.ucsb.edu 


\section{Instrumentation}

\section{Homebuilt 3D Printer}

Digital light processing experiments were performed using a homebuilt 3D printer as previously described. ${ }^{1}$ Briefly, the key components are an Epson 5040UB 3 LCD projector with 2.1X zoom lens $f$ 22.48-46.74 and Zeiss Bronica Zenzanon-S lens, $105 \mathrm{~mm} f 3.5$. Glass chambers and a moving stage were manufactured at the glass shop in the Department of Chemistry and the machine shop in College of Engineering at UC Santa Barbara, respectively.

\section{Scanning Electron Microscopy (SEM)}

SEM images were taken at the UC Santa Barbara Microscopy \& Microanalysis Facility within the California NanoSystems Institute using a Thermo Fisher Apreo C LoVac FEG SEM instrument at an accelerating voltage of $5 \mathrm{kV}$. Prior to imaging, all samples were sputter coated with a thin layer of gold to enhance conductivity and reduce surface charging of polymers. Samples were placed onto a silicon wafer for imaging.

Pore size analysis shown in Figure 8 was performed using Image J. We first measured the areas of pores by highlighting the area of interest and using the area analysis function on ImageJ. The reported diameter values in Figure 8 were calculated by extracting the radius value $(r)$ with the assumption that these pores are circular (i.e., pore area $=\pi r^{2}$ ) for the ease of data presentation.

\section{Optical Microscopy}

Optical microscopy images were taken at the Microfluidics Facility within the UC Santa Barbara California NanoSystems Institute, using a Keyence VHX-5000 Microscope at 10X magnification. Thin slices of printed objects were placed between two glass slides prior to imaging.

\section{Digital Height Gauge}

Thicknesses of polymer coins from kinetic studies were measured using a Mitutoyo digimatic electronic indicator gauge ( $\mathrm{p} / \mathrm{n}$ 543-693) in the Microfluidics Facility within the UC Santa Barbara California NanoSystems Institute. Prior to sample measurements, the height was zero-ed on a glass slide onto which the polymer coins were printed. 


\section{Experimental Details}

\section{Synthesis of $N, N$-Dibutylacrylamide}
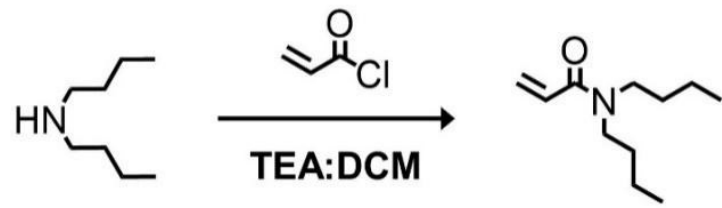

$\mathrm{N}, \mathrm{N}$-dibutylacrylamide was synthesized according to a modified literature procedure. ${ }^{2}$ To a $100 \mathrm{~mL}$ RBF was added dibutylamine $(1.3 \mathrm{~mL}, 7.74 \mathrm{mmol})$, triethylamine $(1.95 \mathrm{~mL}, 14$ $\mathrm{mmol})$, and dichloromethane $(20 \mathrm{~mL})$ under argon. The mixture was cooled to $0{ }^{\circ} \mathrm{C}$, at which point acryloyl chloride $(0.63 \mathrm{~mL}, 7.74 \mathrm{mmol})$ was added in a dropwise fashion. The mixture was stirred for $2 \mathrm{~h}$ at $0{ }^{\circ} \mathrm{C}$ and $20 \mathrm{~h}$ at room temperature, after which it was diluted with dichloromethane $(30 \mathrm{~mL})$ and washed with DI water $(2 \times 50 \mathrm{~mL})$ and brine $(50 \mathrm{~mL})$. The organic layer was dried over anhydrous magnesium sulfate, filtered, and concentrated in vacuo. Distillation under reduced pressure gave the product as a clear oil (1.11 g, $6.03 \mathrm{mmol}, 78 \%$ yield). ${ }^{1} \mathrm{H}$ NMR $\delta(\mathrm{ppm}) 6.48(\mathrm{dd}, \mathrm{J}=16.7,10.3 \mathrm{~Hz}, 2 \mathrm{H}), 6.27$ (dd, J = 16.7, 2.2 Hz, 1H), $5.58(\mathrm{dd}, \mathrm{J}=10.4,2.2 \mathrm{~Hz}, 1 \mathrm{H}), 3.31(\mathrm{t}, 7.5 \mathrm{~Hz}, 2 \mathrm{H}), 3.23(\mathrm{t}, 7.5$ $\mathrm{Hz}, 2 \mathrm{H}), 1.53-1.44(\mathrm{~m}, 4 \mathrm{H}), 1.31-1.21(\mathrm{~m}, 4 \mathrm{H}), 0.88(\mathrm{t}, 7.2 \mathrm{~Hz}, 3 \mathrm{H}) 0.86(\mathrm{t}, 7.2 \mathrm{~Hz}, 3 \mathrm{H})$. ${ }^{13} \mathrm{C}$ NMR $\left(125 \mathrm{MHz}, \mathrm{CDCl}_{3}\right) \delta$ (ppm) 165.9, $127.6(2 \mathrm{C}), 127.3$ (2C), 47.9, 46.6, 31.9, 29.7, $20.3,20.0,14.0,13.9$.

\section{Synthesis of Poly(N,N-dibutylacrylamide)}

Polydibutylacrylamide. To a $20 \mathrm{~mL}$ scintillation vial was added $\mathrm{N}, \mathrm{N}$-dibutylacrylamide (100 $\mathrm{mg}, 0.55 \mathrm{mmol})$, AIBN $(0.09 \mathrm{mg}, 0.006 \mathrm{mmol})$, and DMF $(5 \mathrm{~mL})$. The reaction mixture was sparged with argon for 10 min before being heated to $60^{\circ} \mathrm{C}$ and stirred for $20 \mathrm{~h}$. The mixture was then precipitated into diethyl ether and dried in vacuo to give the polymer as a white solid. ${ }^{1} \mathrm{H}$ NMR $\delta(\mathrm{ppm}) 3.3-2.8\left(-\mathrm{CON}-\mathrm{CH}_{2}-\mathrm{CH}_{2}-\right)$, 2.4-1.0 (overlapping, backbone $-\mathrm{CH}_{2}-\mathrm{CH}-$ and butyl $\left.-\mathrm{CH}_{2}-\mathrm{CH}_{2}-\right), 0.8-0.6\left(-\mathrm{CH}_{2}-\mathrm{CH}_{3}\right)$. DSC $\mathrm{T}_{\mathrm{g}}=28{ }^{\circ} \mathrm{C}$.

Table S1. Resin formulation 1.

\begin{tabular}{cccccccccc} 
& BA & HEAm & DEAm & TEGDA & EB & Borate & H-Nu254 & Sudan IV & Sudan B \\
\hline Amount & $4 \mathrm{~mL}$ & $4 \mathrm{~mL}$ & $2 \mathrm{~mL}$ & $59 \mu \mathrm{L}$ & $3 \mathrm{mg}$ & $19 \mathrm{mg}$ & $19 \mathrm{mg}$ & $7.5 \mathrm{mg}$ & $4.5 \mathrm{mg}$
\end{tabular}


Table S2. Resin formulations 2 and 3 (top, bottom).

\begin{tabular}{cccccccccc} 
& EGMEA & HEAm & DEAm & TEGDA & EB & Borate & H-Nu254 & Sudan IV & Sudan B \\
\hline Amount & $5 \mathrm{~mL}$ & $2 \mathrm{~mL}$ & $3 \mathrm{~mL}$ & $59 \mu \mathrm{L}$ & $3 \mathrm{mg}$ & $19 \mathrm{mg}$ & $19 \mathrm{mg}$ & $7.5 \mathrm{mg}$ & $4.5 \mathrm{mg}$ \\
& & & & & & & & & \\
& EGMEA & HEAm & DBAm & TEGDA & EB & Borate & H-Nu254 & Sudan IV & Sudan B \\
\hline Amount & $5 \mathrm{~mL}$ & $2 \mathrm{~mL}$ & $3 \mathrm{~mL}$ & $59 \mu \mathrm{L}$ & $3 \mathrm{mg}$ & $19 \mathrm{mg}$ & $19 \mathrm{mg}$ & $7.5 \mathrm{mg}$ & $4.5 \mathrm{mg}$
\end{tabular}

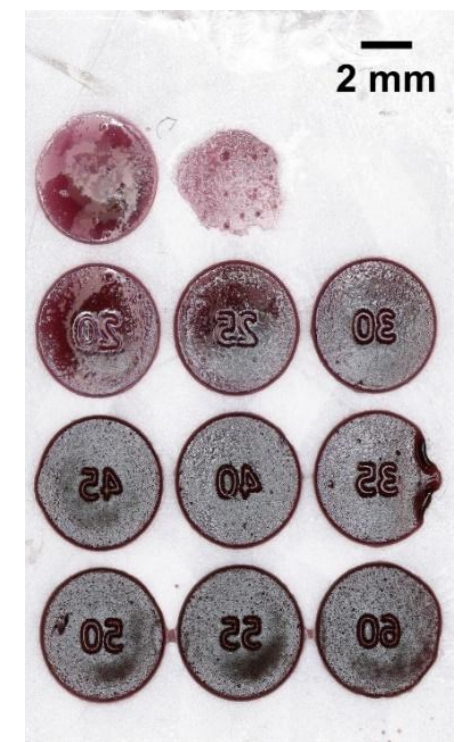

Figure S1. Optical image of polymer coins printed on a glass slide with varying exposure times of 5 to $60 \mathrm{~s}$ in $5 \mathrm{~s}$ increments. 

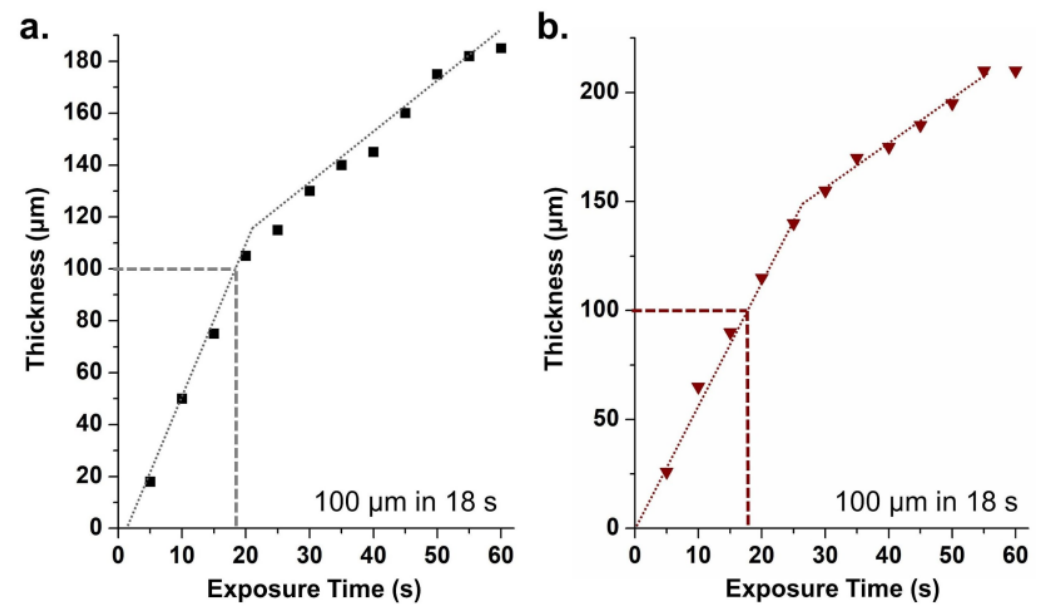

Figure S2. Kinetic results of resins a. without and b. with microspheres (15 wt \%). Dotted rectangular box is included to demonstrate the time it takes to cure $100 \mu \mathrm{m}$ thick coin.
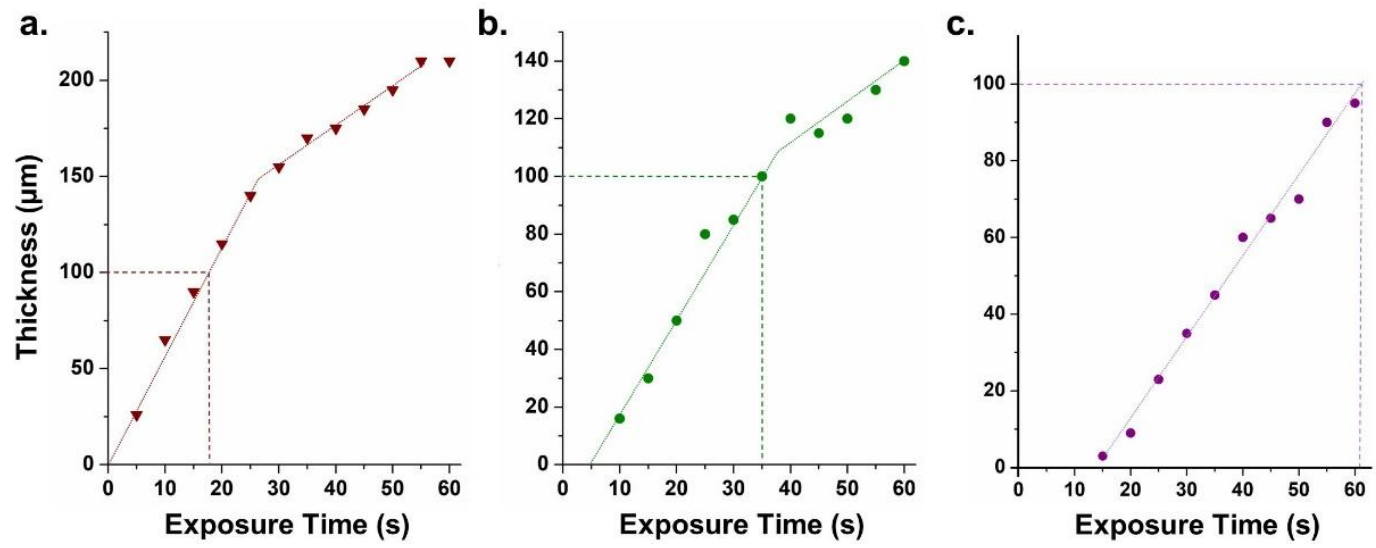

Figure S3. Kinetic study results of a. resin (1), b. resin (2), and c. resin (3) with 15 wt \% microspheres.

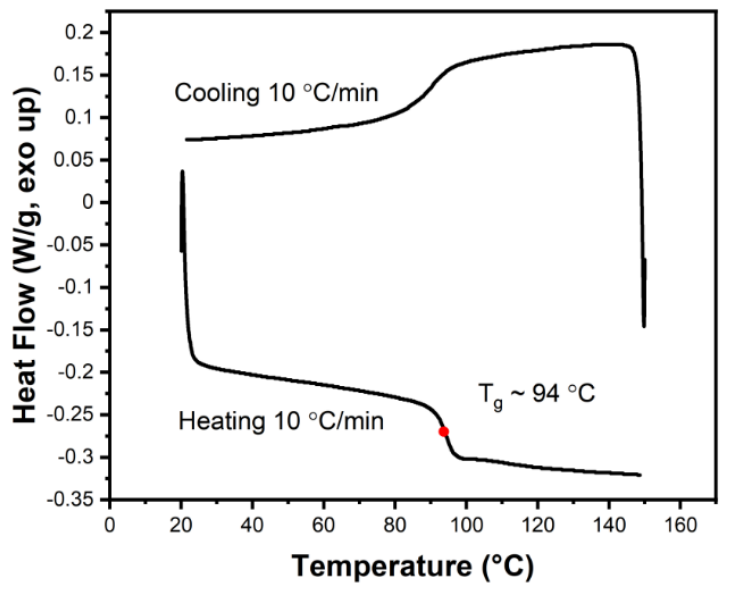

Figure S4. DSC analysis of expanded microspheres. 


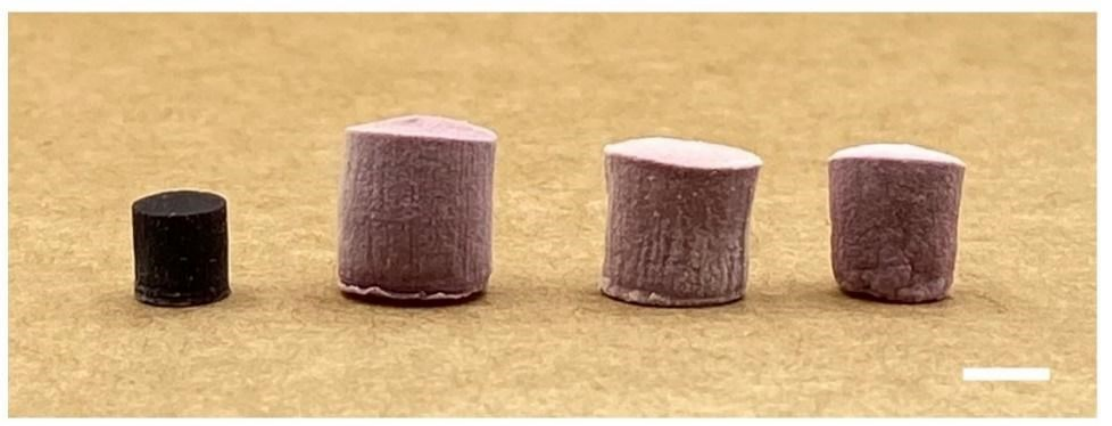

Figure S5. Photo of unexpanded (left) and expanded cylinders (second left to right) printed from resins (1-3). Scale bar is $5 \mathrm{~mm}$.
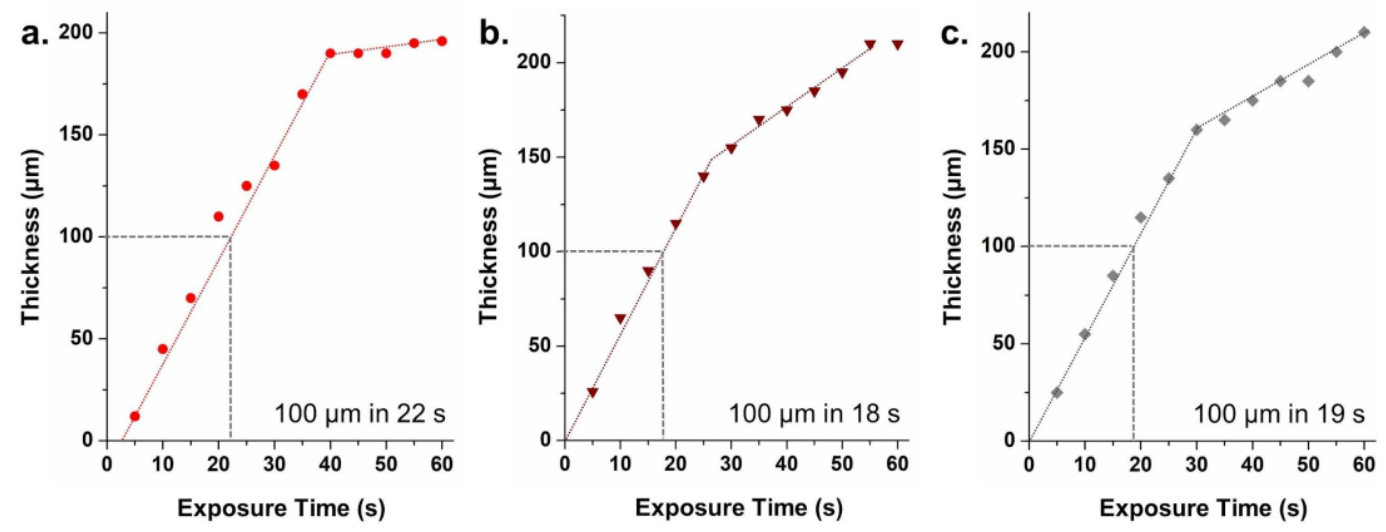

Figure S6. Kinetic results of resins with 15 wt $\%$ microspheres and different concentrations of crosslinkers a. 0.14 b. 0.27 , c. and $0.4 \mathrm{~mol} \%$. Dotted rectangular box is included to demonstrate the time it takes to cure $100 \mu \mathrm{m}$ thick coin. 


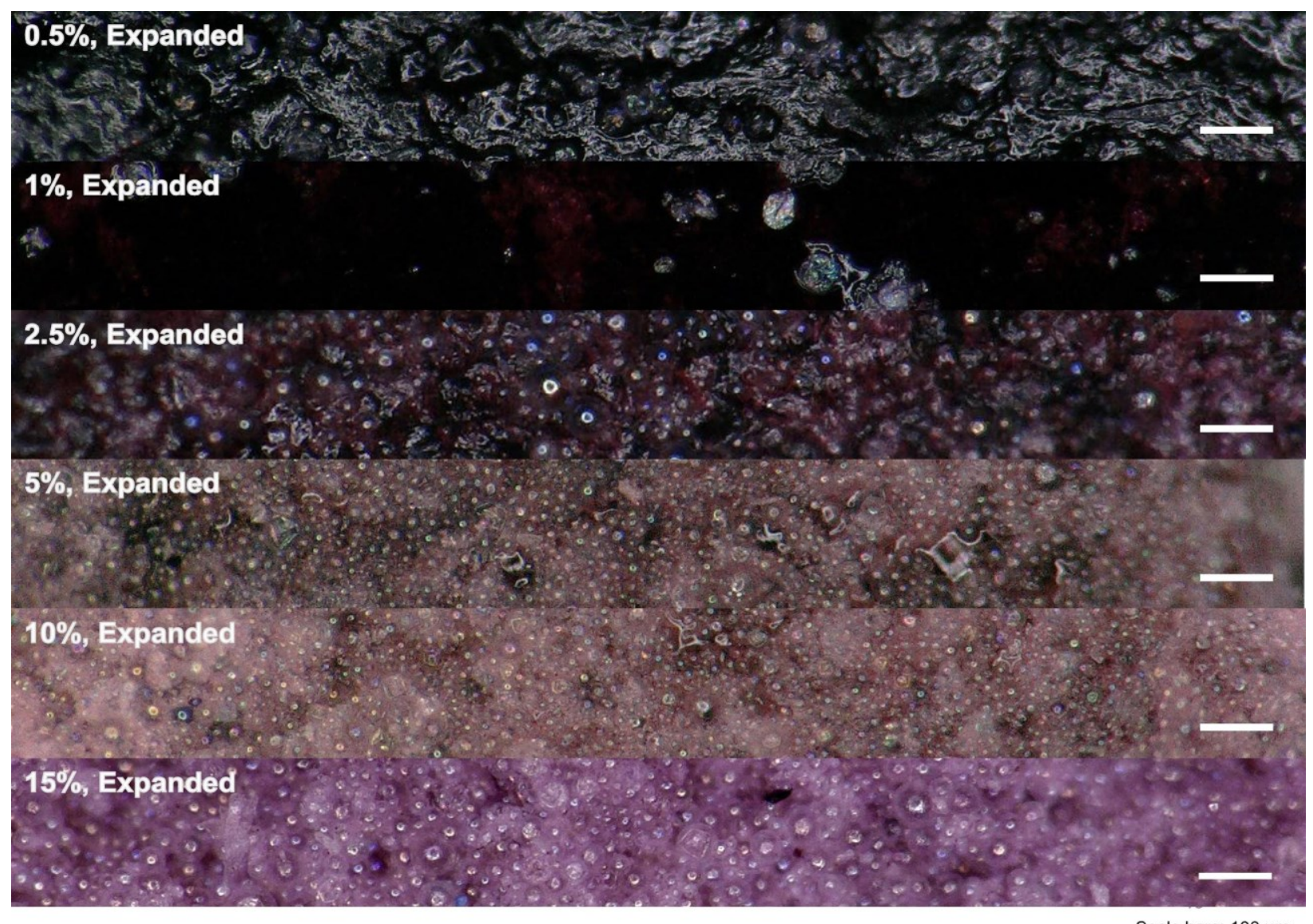

Scale bars: $100 \mu \mathrm{m}$

Figure S7. Optical images of top surfaces of expanded polymer foams containing different concentrations of microspheres. As the volume fraction of microspheres increases, the color of the matrix becomes lighter because the volume fraction of the matrix decreases upon expansion. Scale bars are $100 \mu \mathrm{m}$. 


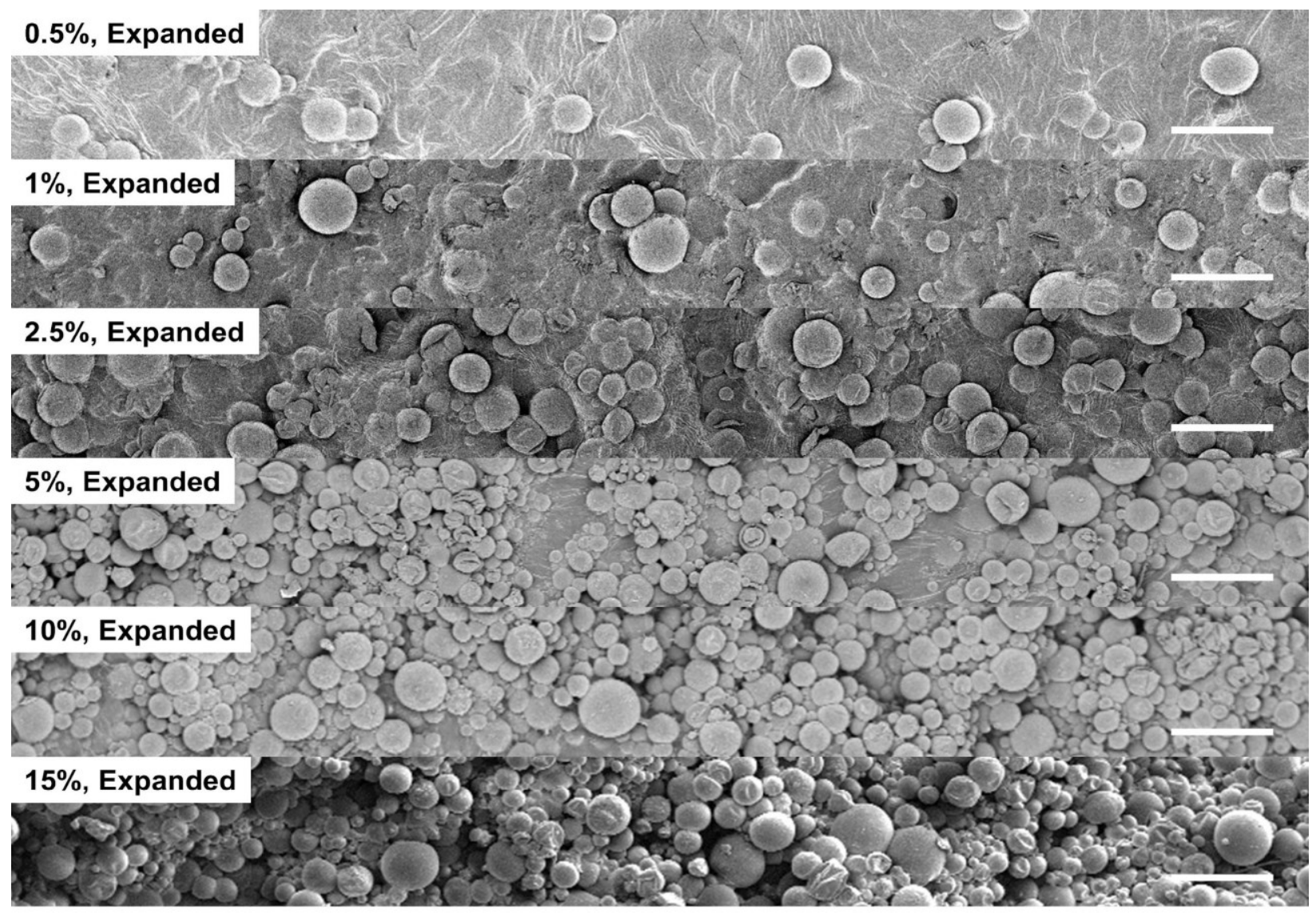

Scale bars: $100 \mu \mathrm{m}$

Figure S8. SEM images of top surfaces of expanded polymer foams containing different concentrations of microspheres. Scale bars are $100 \mu \mathrm{m}$.

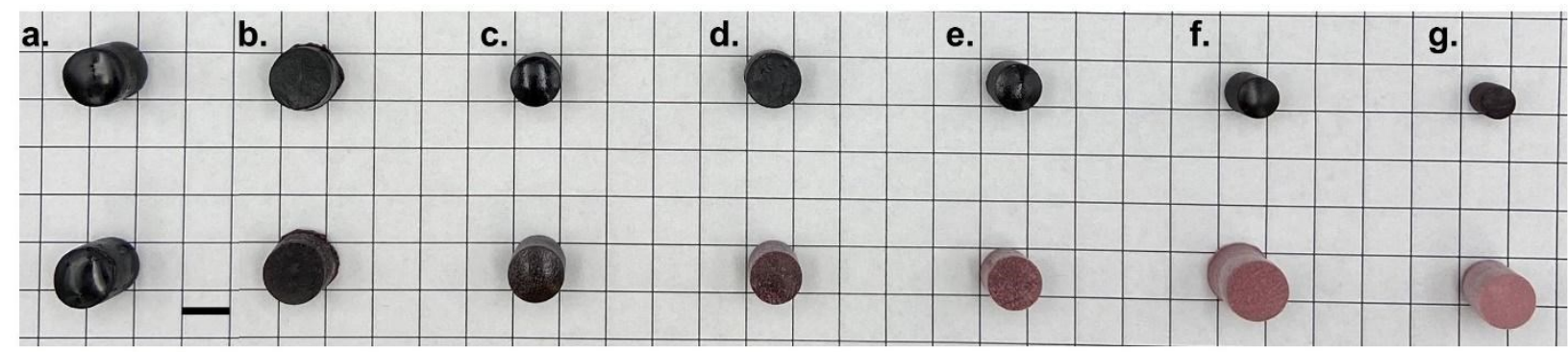

Figure S9. Photograph of 3D printed cylinders with a. 0 , b. 0.5 , c. 1 , d. 2.5 , e. 5 , f. 10 , and g. $15 \mathrm{wt} \%$ of microspheres for size analysis before (top) and after (bottom) the thermal treatment. Note that the pre-expansion specimen size is reduced for the high microsphere weight-fraction samples in order to achieve expanded samples with similar final size. Scale bar is 0.5 in. 

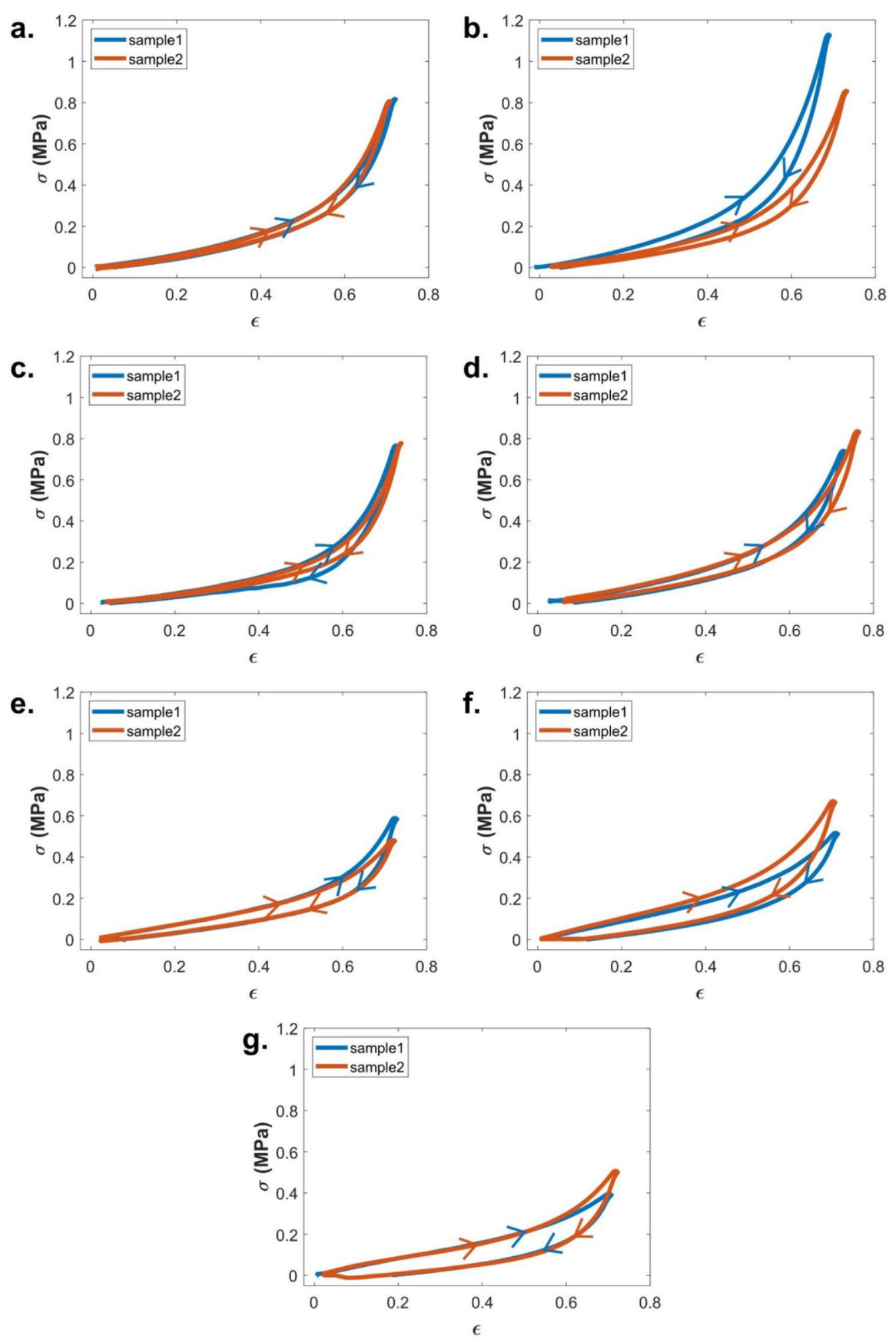

Figure S10. Stress-strain curves of polymer foams with different microsphere contents obtained via uniaxial compression testing. Two specimens were tested at each wt \%: a. 0 , b. 0.5 , c. 1 , d. 2.5 , e. 5 , f. 10 , and g. 15 . 


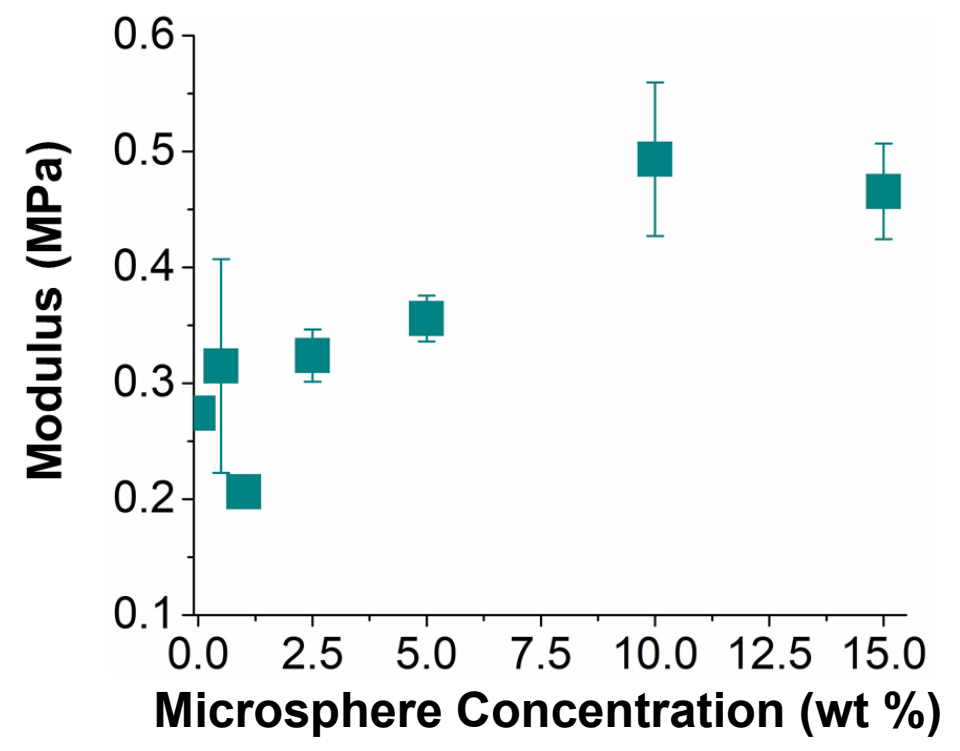

Figure S11. Compressive modulus of 3D printed foams at various wt $\%$ microspheres. Error bars represent standard deviations for modulus measurements of two distinct samples at various wt \% microspheres. 

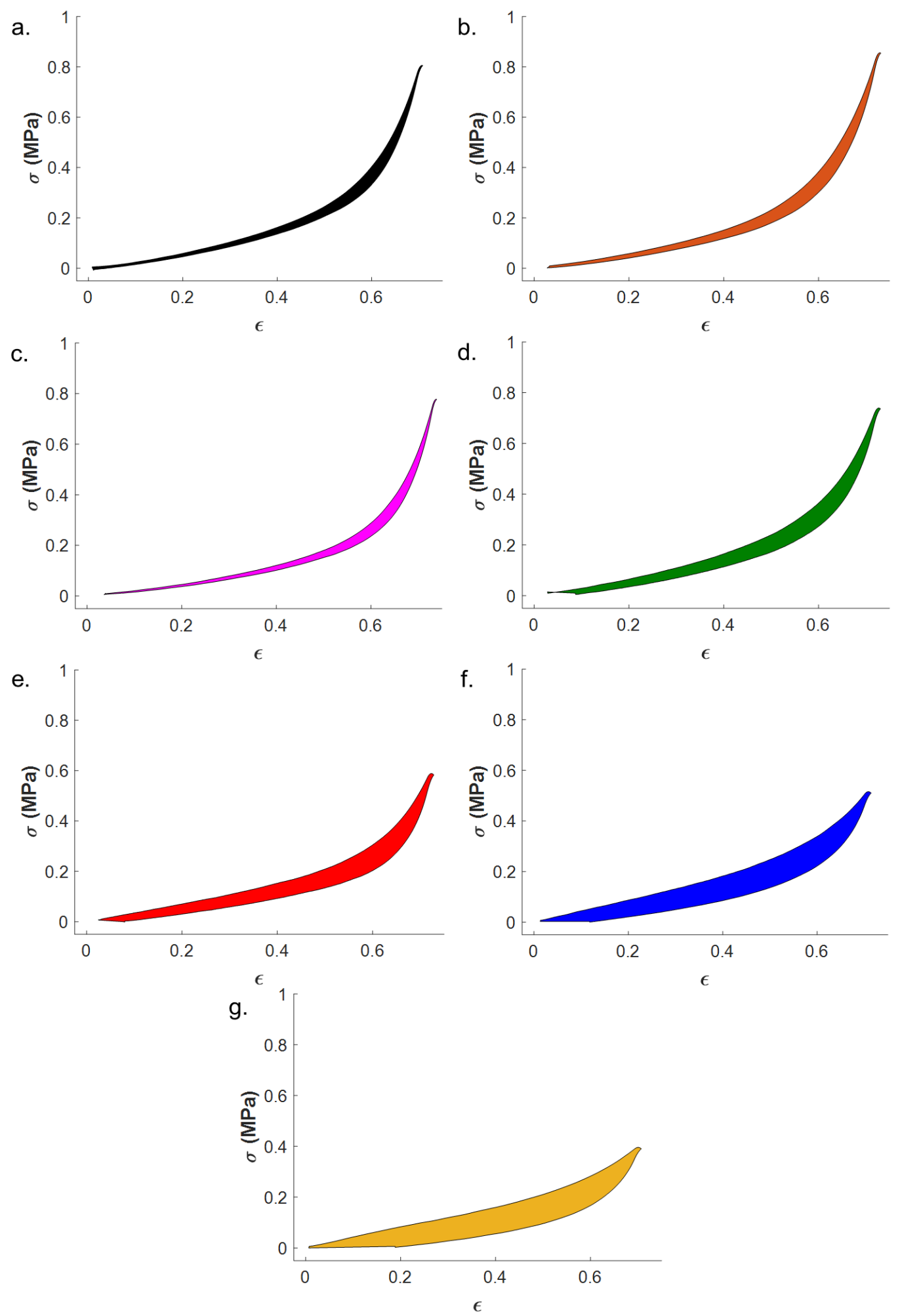

Figure S12. A comparison of the hysteresis loop at various wt \% microspheres: $\mathbf{a} . \mathbf{0}, \mathbf{b}$. 0.5 , c. 1 , d. 2.5 , e. 5 , f. 10 , and g. 15 . The area between the loading and unloading curves of $3 \mathrm{D}$ printed foams is calculated to characterize the energy dissipation. 

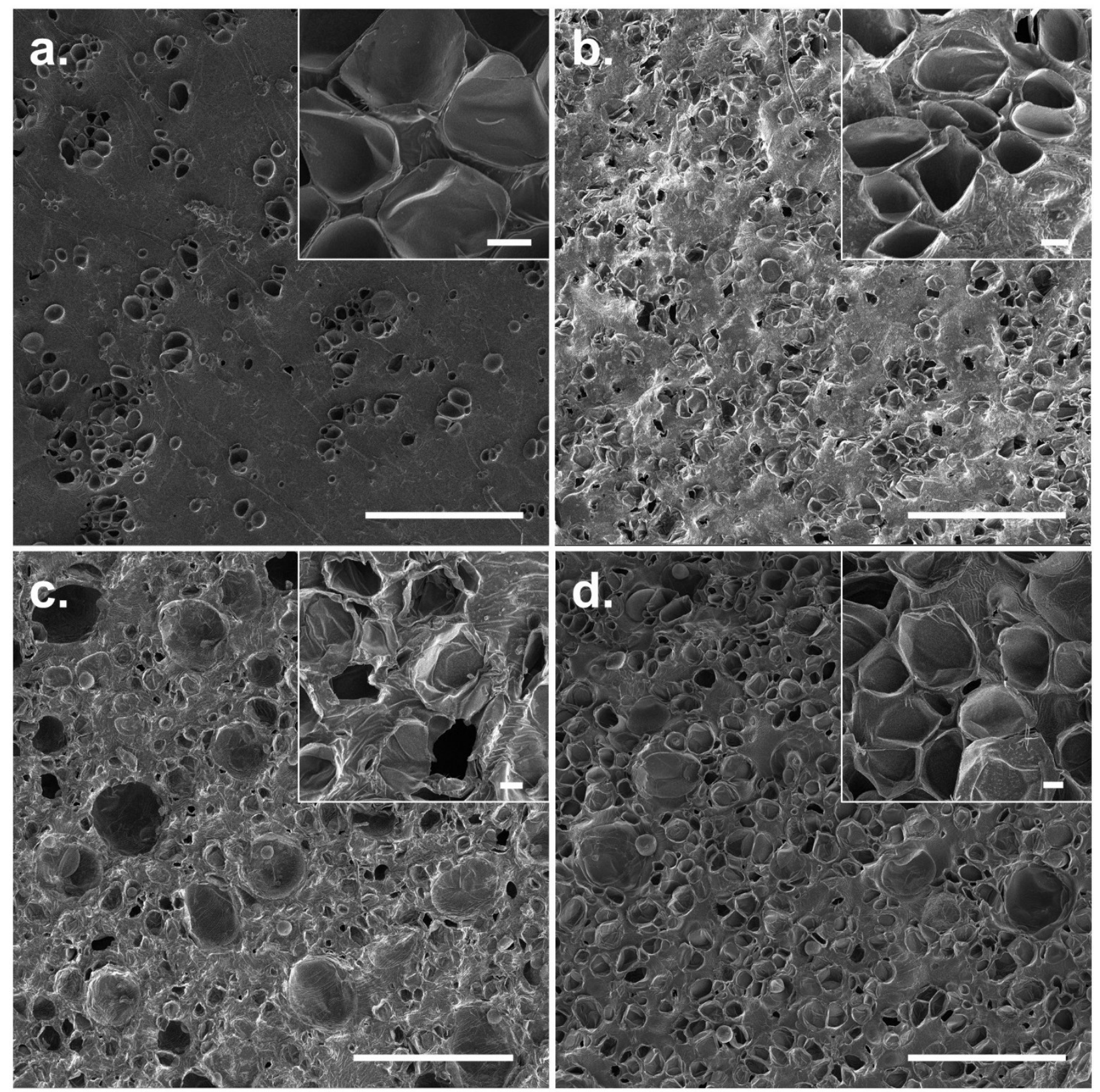

Figure S13. Cross-sectional SEM images of printed foams after compression testing, showing possible plastic deformation of the shell walls. a. 2.5 , b. 5, c. 10 , and d. $15 \mathrm{wt} \%$ microspheres. Scale bars are $10 \mu \mathrm{m}$ (inset) and $250 \mu \mathrm{m}$. 

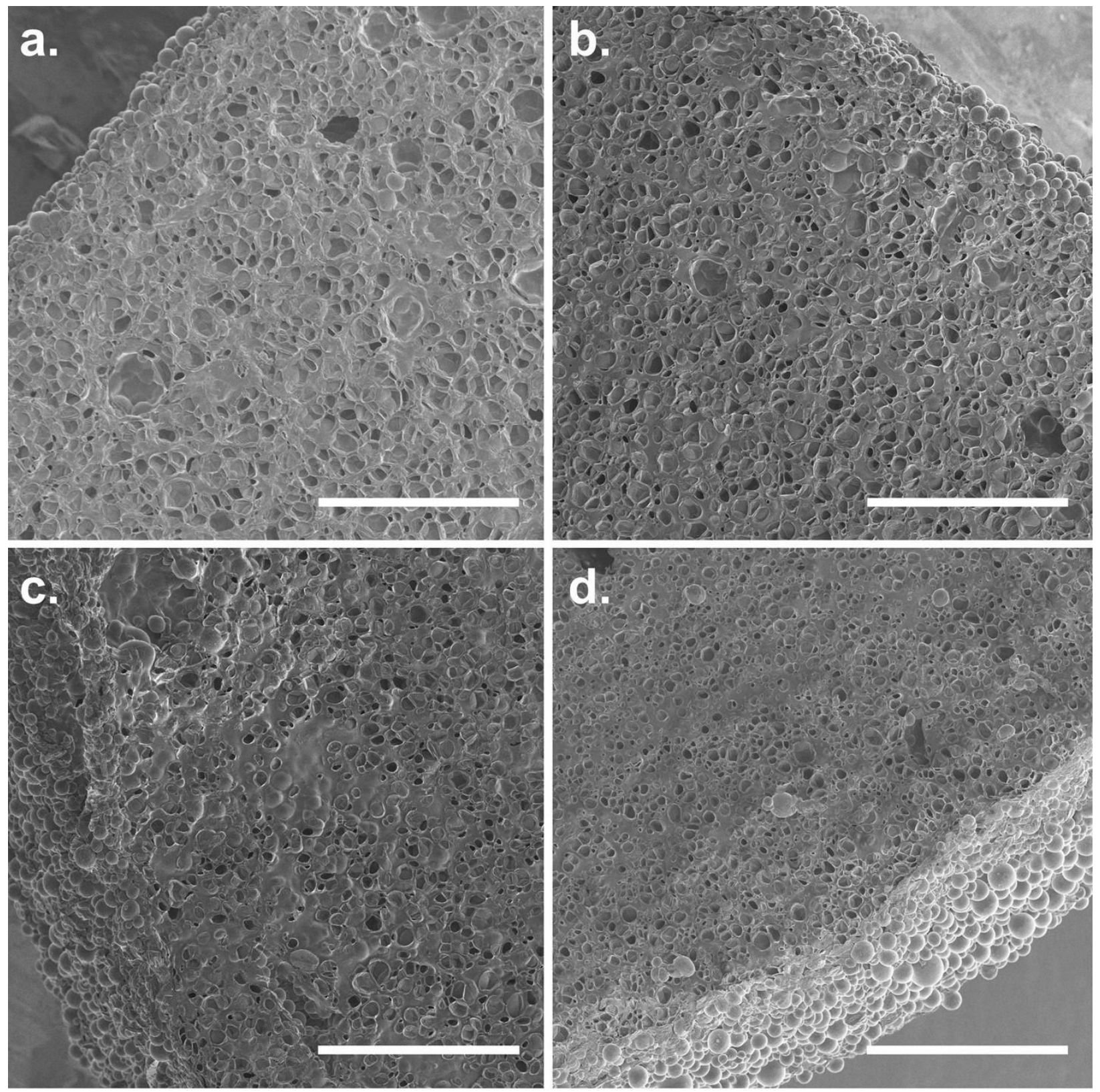

Figure S14. Cross-sectional SEM images of expanded foams with a. 0.14, b. 0.27, c. 0.54 , and d. $1.08 \mathrm{~mol} \%$ TEGDA. Scale bars are $500 \mu \mathrm{m}$.

\section{References}

(1) Dolinski, N. D.; Page, Z. A.; Callaway, E. B.; Eisenreich, F.; Garcia, R. V.; Chavez, R.; Bothman, D. P.; Hecht, S.; Zok, F. W.; Hawker, C. J. Solution Mask Liquid Lithography (SMaLL) for One-Step, Multimaterial 3D Printing. Adv. Mater. 2018, 30, 1800364.

(2) Taaning, R. H.; Lindsay, K. B.; Skrydstrup, T. Some Unusual Reactivities in the Sml2Mediated Reductive Coupling of Acrylamides and Acrylates with Imides. Tetrahedron 2009, 65, 10908-10916. 